\title{
Genome-wide characterisation of the binding repertoire of small molecule drugs
}

\author{
Lee Makowski* and Diane J. Rodi \\ Biosciences Division, Argonne National Laboratory, Argonne, Illinois 60439, USA \\ *Correspondence to: Tel: +1 630252 3917; Fax: +1 630252 3853; E mail: lmakowski@anl.gov
}

Date received (in revised form): 21st August 2003

\begin{abstract}
Most, if not all, drugs interact with multiple proteins. One or more of these interactions are responsible for carrying out the primary therapeutic effects of the drug. Others are involved in the transport or metabolic processing of the drug or in the mediation of side effects. Still others may be responsible for activities that correspond to alternate therapeutic applications. The potential clinical impact of a drug and its cost of development are affected by the sum of all these interactions. The drug development process includes the identification and characterisation of a drug's clinically relevant interactions. This characterisation is presently accomplished by a combination of experimental laboratory techniques and clinical trials, with increasing numbers of patient participants. Efficient methods for the identification of all the molecular targets of a drug prior to clinical trials could greatly expedite the drug development process. Combinatorial peptide and cDNA phage display have the potential for achieving a complete characterisation of the binding repertoire of a small molecule. This paper will discuss the current state of phage display technology, as applied to the identification of novel receptors for small molecules, using a successful application with the drug Taxol ${ }^{\mathrm{TM}}$ as an example of the technical and theoretical benefits and pitfalls of this method.
\end{abstract}

Keywords: phage display, drug target, molecular recognition, drug receptor, Taxol ${ }^{\mathrm{TM}}, \mathrm{Bcl}-2$

\section{Introduction}

The concept of a receptor as the component of an organism with which a chemical agent interacts was based originally on the independent work of Paul Ehrlich and J. N. Langley during the late nineteenth century. Pharmaceutical agents are generally believed to exert their therapeutic effect by binding to a particular protein or nucleic acid target. ${ }^{1}$ Both natural product and synthetic chemical drugs, however, can and do have multiple macromolecule-binding partners (Table 1), ${ }^{2-48}$ such as metabolic breakdown enzymes (ie cytochrome P450 enzymes), side effect-mediating targets and, in some cases, secondary therapeutic targets (see aspirin and Taxol ${ }^{\mathrm{TM}}$ below as specific examples). Recognition of the binding promiscuity of drug molecules is reflected in the recent assembly of a publicly accessible web-based therapeutic target database. ${ }^{49}$

For a drug to reach the market, an average input of 14 years and US\$359 million is required. ${ }^{50}$ The assessment of toxicity, side effects and metabolic breakdown pathways consumes a large percentage of this investment. ${ }^{51-53}$ The speed with which a drug passes through the various stages of the drug discovery process can be a critical factor for success. Novel strategies that provide information about the potential target proteins of a small molecule are badly needed to augment the current drug development process. A complete accounting of the repertoire of targets for a particular drug provides important information towards a complete understanding of the mode of action of a drug, as well as the prediction of potential complications from its use in the clinic. Detection of potential toxicity and side effect properties early on during drug development can translate into large financial savings and lowered patient risk, as efforts can be redirected towards drug leads that are more likely to be safe for patient use. Unfortunately, identifying macromolecules that bind to small molecule drugs can be a slow and laborious process, particularly if the target(s) are expressed at low levels in their respective tissue(s). Although computer methods for toxicity prediction offer a fast, attractive solution to this problem, ${ }^{54-56}$ even the best of this predictive software ${ }^{57}$ generates hypotheses based upon crystal structure-based rigid protein docking studies. In many cases, small molecules (ie non-peptide molecules of less than about 1,000 Daltons) appear to interact with their receptors through regions that are disordered prior to the interaction. ${ }^{58}$ This suggests that computer-based docking strategies may be limited in their success with a subset of potential drug/protein interactions. 
Table I. A sample list of drugs on the market for which multiple protein/macromolecule targets have been identified or implied' in the literature

\begin{tabular}{|c|c|c|c|}
\hline Drug & Target & Physiological effect & $\begin{array}{l}\text { Experimentally } \\
\text { confirmed? }\end{array}$ \\
\hline \multirow[t]{6}{*}{$\mathrm{Taxol}^{\mathrm{TM}}$} & $\beta$-Tubulin & Mitotic block & Yes $^{2}$ \\
\hline & $\mathrm{Bcl}-2$ & Apoptosis & Yes $^{3}$ \\
\hline & P-glycoprotein & Drug resistance & $Y_{e s}^{4,5}$ \\
\hline & CDI8 & LPS-like activity & Yes $^{6}$ \\
\hline & Topoisomerase II & Mitotic block? & Yes $^{7}$ \\
\hline & Hsp90 & $?$ & Yes $^{8}$ \\
\hline \multirow[t]{6}{*}{ Aspirin } & $\operatorname{cox}$ & Anti-inflammatory activity & Yes $^{9}$ \\
\hline & IKKK $\beta$ & Anti-inflammatory activity & Yes $^{10}$ \\
\hline & Carbonic anhydrase & Anti-inflammatory activity & Yes $^{\prime \prime}$ \\
\hline & Antithrombin III & Anticoagulant activity & Yes $^{12}$ \\
\hline & LCHAD & Beta-oxidation inhibition & Yes $^{13}$ \\
\hline & Fatty acid-binding protein & Peroxisome proliferator activity & Implied ${ }^{14}$ \\
\hline \multirow[t]{4}{*}{ Gentamicin } & I6S ribosomal RNA & Antibiotic activity & Yes $^{15}$ \\
\hline & $\alpha 9 \mathrm{nAChR}$ & Side effects on organ of Corti & Yes $^{16,17}$ \\
\hline & Glutamate dehydrogenase & Nephrotoxicity & Yes $^{18}$ \\
\hline & Steroidogenic enzymes? & Sperm count decline & Implied ${ }^{19}$ \\
\hline \multirow[t]{3}{*}{ Ibuprofen } & Prostaglandin $\mathrm{H}(2)$ synthase-I & Anti-inflammatory activity & $\mathrm{Yes}^{20}$ \\
\hline & Steroid sulfotransferase & Toxicity & Yes $^{21}$ \\
\hline & $?$ & PMN migration inhibition & Implied ${ }^{22}$ \\
\hline \multirow[t]{2}{*}{ Saquinavir } & HIV protease & Anti-HIV activity & Yes $^{23}$ \\
\hline & PPAR $\gamma$ & Fat metabolism effects & $\mathrm{Yes}^{24}$ \\
\hline \multirow[t]{6}{*}{ Neomycin B } & I6S ribosomal RNA & Antibiotic activity & Yes $^{25}$ \\
\hline & Multiple ribozymes & $?$ & $Y_{e s}^{26,27}$ \\
\hline & $\alpha 9 \mathrm{nAChR}$ & Side effects on organ of Corti & Yes $^{16}$ \\
\hline & Inositol phospholipids & Inhibition of phospholipase C & Yes $^{28}$ \\
\hline & RRE RNA from HIV & Anti-HIV activity & $\mathrm{Yes}^{29}$ \\
\hline & Glutamate dehydrogenase & Nephrotoxicity & Yes $^{18}$ \\
\hline \multirow[t]{3}{*}{ Penicillin } & $\beta$-Lactamase & Antibiotic activity & Yes $^{30}$ \\
\hline & GSH S-transferase & ? & Yes $^{31}$ \\
\hline & $?$ & IFN- $\gamma$ modulation & Implied ${ }^{32}$ \\
\hline
\end{tabular}


Table I. Continued

\begin{tabular}{|c|c|c|c|}
\hline Drug & Target & Physiological effect & $\begin{array}{l}\text { Experimentally } \\
\text { confirmed? }\end{array}$ \\
\hline \multirow[t]{3}{*}{ Genistein } & Tyrosine protein kinase & Multiple cellular effects & Yes $^{33-35}$ \\
\hline & Topoisomerase I and II & Multiple cellular effects & Yes $^{36,37}$ \\
\hline & Oestrogen receptor $\beta$ & Partial agonist activity & $Y_{e s}^{38,39}$ \\
\hline \multirow[t]{2}{*}{ Fluoroquinolones } & GyrA gene product & Antibiotic activity & $Y_{e s}^{40}$ \\
\hline & ParC (topoisomerase IV) gene product & Antibiotic activity & Yes $^{41,42}$ \\
\hline \multirow[t]{2}{*}{ CGP64222 } & HIV TAR RNA & Anti-HIV activity & $Y_{e s}^{43}$ \\
\hline & CXCR4 coreceptor & Anti-HIV activity & $Y_{e s}^{44}$ \\
\hline \multirow[t]{2}{*}{ Flavopiridol } & Cyclin-dependent kinase & Anti-cancer activity & $Y_{e s}{ }^{45}$ \\
\hline & Duplex DNA & Anti-cancer activity & $\mathrm{Yes}^{46}$ \\
\hline \multirow[t]{2}{*}{ Coumarins } & DNA gyrase & Antibiotic activity & Yes $^{47}$ \\
\hline & hel gene product(s) & Antibiotic activity & Possible 48 \\
\hline
\end{tabular}

Note: ' 'Implied' means that there is no direct data to substantiate the direct binding of that drug to that particular target, merely indirect evidence.

LCHAD: long chain 3-hydroxyacyl-CoA-dehydrogenase; nAChR: neuronal nicotinic acetylcholine receptor; COX: cyclooxygenase; PPAR: peroxisome proliferator-activated receptor; RRE: Rev response element; GSH: glutathione S-transferase; TAR: transactivation response; LPS: lipopolysaccharide; PMN: polymorpho-nuclear leukocyte.

In this paper, we outline a strategy for identifying the targets of small molecules based on the screening of protein or combinatorial peptide libraries displayed on phage particles. The ultimate goal is the complete delineation of all the targets for a small molecule. Since known receptors are mainly proteins, the discussion will be limited to the identification of protein targets. These strategies have been validated using libraries of cDNA expression products ${ }^{59-61}$ and libraries of combinatorial peptides. The latter have been used to identify a novel target for Taxol ${ }^{\mathrm{TM}}, 3$ and carry out an in vitro approach to the identification of ATP-binding proteins within entire proteomes (Makowski et al., in preparation).

\section{The number of targets of a drug}

Most, if not all, drugs interact with multiple macromolecules. Some of these molecules conform to the concept of a 'receptor', in that they are responsible for mediating the primary therapeutic effects of the drug. Other target molecules would not classically be referred to as receptors because they are involved in transport, chemical processing or the side effects of the drug. Some of these interactions are non-specific, such as the interactions between hydrophobic drugs and serum proteins. These interactions are, however, critical elements in defining the clinical effect of the drug. Table 1 lists the known 'specific' macromolecular targets for a few representative drugs. Some of the best drugs may be more effective than related molecules because they bind two or more targets relevant to their clinical action. Aspirin, the most potent anti-inflammatory agent identified to date, has at least three targets that mediate antiinflammatory activity. The anti-cancer activity of Taxol ${ }^{\mathrm{TM}}$ is greater than that of other mitotic spindle poisons, presumably because it interacts with the anti-apoptotic protein $\mathrm{Bcl}-2$, as well as with $\beta$-tubulin. ${ }^{3}$

A small molecule that binds to no macromolecules (if such a thing exists) will be biologically inert. Conversely, a small molecule that binds to hundreds of proteins may possess numerous therapeutic applications but will have a very high chance of being toxic, as any one of these interactions might disrupt an essential molecular function. A good drug, therefore, should be expected to bind to somewhere between one and a dozen proteins. One, or possibly a few, of these interactions will mediate the primary activity of the drug. The necessity of specific action demands that small molecule drugs bind with high affinity and specificity to a relatively limited number of protein targets.

Between 3,000 to 10,000 new disease-related targets are expected to emerge out of the Human Genome Project and related sequencing projects such as the Microbial Genome Program of the US Department of Energy. ${ }^{62}$ Parallel synthesis or combinatorial chemistry is similarly expected to generate a coordinate build-up of lead compounds. This concurrent accumulation of targets and drug candidates may not automatically translate into an increased introduction of Food and Drug Administration-approved pharmaceuticals into the medical marketplace. Although high-throughput combinatorial chemistry can create staggering molecular diversity, this diversity may be irrelevant or only semi relevant to the drug target population. 
Natural products and their derivatives have evolved to bind to a relatively limited number of proteins in order to be non-toxic to the organism from which they derive. The only exceptions to this rule are a few widely used metabolites, such as ATP, that bind to many different proteins. Synthetic molecules are not so limited. No evolutionary pressure has restricted the number of their biological targets on the basis of inactivity or toxicity. It is possible that the members of many classes of synthetic molecules will bind to many different macromolecules, thus increasing the percentage that will fail toxicity screening. This effect may be partially responsible for the difficulties that combinatorial chemistry has had in superseding natural product leads in the drug development pipeline. There has been a growing trend towards the synthesis of focused, natural product-like libraries ${ }^{63}$ which 'partake of the "wisdom" of natural products' ${ }^{64}$ This focused library approach may limit the chemical diversity to a biologically relevant subpopulation.

\section{Methods for identification of the molecular targets of a small molecule}

Conceptually, it should be possible to develop methods that are capable of identifying all the targets of a small molecule drug or drug candidate. One could conceive of an ideal tool a biological interaction chip containing an indexed set of all the molecular surfaces available to a drug molecule within the human body (and within human pathogens and animal models for human pathologies). A simple screen, allowing for very high sensitivity detection of a drug candidate bound to each of the proteins on this chip, could then be used to identify the dozen or so targets expected for a successful drug candidate and rule out promiscuous, potentially toxic drug candidates. An ideal, universal system of this kind is far beyond the relatively simple protein or peptide chips currently under development. ${ }^{65}$ What is available now?

The most obvious path to a full accounting of the targets of a small molecule is to create an affinity column containing an immobilised form of the small molecule (preferably attached via tethers to at least two different locations so that every portion of the small molecule is free for binding in at least one of the tagged forms). A cell extract poured through the column will allow those molecules with high affinity to the drug to be bound to the column. Identification of those targets, either by gel electrophoresis and/or mass spectrometry, provides an accounting of the molecules with high affinity for the immobilised small molecule. This strategy has been successful for the identification of numerous molecular targets $^{66}$ and will continue to be used. It may be difficult to identify poorly expressed targets, targets that are membrane bound, or large complexes via this technique, as well as to distinguish true positives from false positives.

\section{Bacteriophage display libraries}

An efficient way of improving the signal-to-noise ratio in an affinity selection process is to physically link a phenotype to a biologically 'amplifiable' genotype. Several such 'surface display systems' are now in use (such as ribosome display and cell surface display) ${ }^{67-69}$ and some of these have been validated for novel drug-protein interaction identification (see McPherson et al., ${ }^{70}$ where a tagged version of the drug FK506 was used as a probe molecule against libraries of mRNA-protein fusion molecules constructed from human liver, kidney and bone marrow transcripts). The simplest and most widespread cost-effective systems for carrying out this linkage, however, are bacteriophage display libraries. ${ }^{71}$ In these libraries, the DNA encoding a protein or peptide is inserted into the gene of a structural protein of the phage in such a way that its expression product is displayed on the surface of the phage as a fusion to the structural protein, but without disrupting an essential function of that structural protein. A library of phages, each displaying a different expression product, is screened for members that exhibit affinity to a target (using an affinity column, as described above, or a related technique referred to as 'biopanning, ${ }^{72}$ ). Even if this affinity selection results in only a handful of positive 'hits', because of the linkage of phenotype to genotype, it is possible to characterise these 'hits' because the affinity-selected phage can be grown and the sequence of the inserted DNA ascertained. This process circumvents the need to carry out highly sensitive chemical analysis of small amounts of material separated via binding to the drug target. The majority of bacteriophage display systems have been based upon the filamentous phage M13, ${ }^{71}$ but the inherent limitations of a biological system based upon membrane extrusion for replication ${ }^{73}$ has led to the development of phage display systems based upon such lytic phages as $\mathrm{T} 7$ and $\lambda .^{74}$

\section{cDNA expression product libraries}

It is now possible to construct libraries of cDNA expression products displayed on the surface of phage particles and to screen them for members exhibiting affinity to small molecules. cDNA sequences are inserted into the gene for a structural protein in such a way that the expression product is displayed on the surface of a virion. Even if only a single phage particle is selected for affinity to a small molecule, it is possible to identify the gene product responsible because the virus can be grown in quantities sufficient for sequencing the viral DNA which contains an insert coding for the gene product displayed on the surface. A similar approach using genomic libraries is also possible, whereby whole genomes are chemically fragmented and cloned into the phage genome. ${ }^{75-79}$ A principal shortcoming of this method is that many gene products do not fold properly on a phage surface, particularly large proteins and membrane proteins. This drawback can be alleviated by the use of genomic DNA fragmented 
into epitope-sized coding pieces as mentioned above. A second problem with full-length protein display is that most phage display systems append the foreign protein onto the carboxy terminus of the phage structural protein, due to the structural requirements of the viral particle (such as a number of commercially available $\mathrm{T} 7 \mathrm{cDNA}$ display libraries). This results in the translation of many cDNA sequences in the incorrect reading frame, as well as the inclusion of 'nonsense' peptides translated from $3^{\prime}$ non-coding regions. A number of systems are available which attach the foreign protein to the amino terminus of the phage structural protein, thus weeding out DNA insert sequences which do not fully translate in-frame to the beginning of the phage structural protein gene (for example, M13 gene IIIbased libraries). ${ }^{74}$

Several successful uses of this strategy have been reported. Sche et al., used a cDNA phage display library to isolate clones of the FKBP12 protein from a human brain cDNA library using a biotinylated FK506 probe molecule. ${ }^{59,60}$ During multiple rounds of affinity selection with the immobilised drug molecule, the FKBP12 gene emerged as the dominant library member with detection possible via polymerase chain reaction amplification after the second round of affinity selection. Six rounds of affinity selection with the modified drug were required for the FKBP gene to be the predominant clone within the selected population. A similar phage-based approach has been used to identify the protein hNopp140 as a

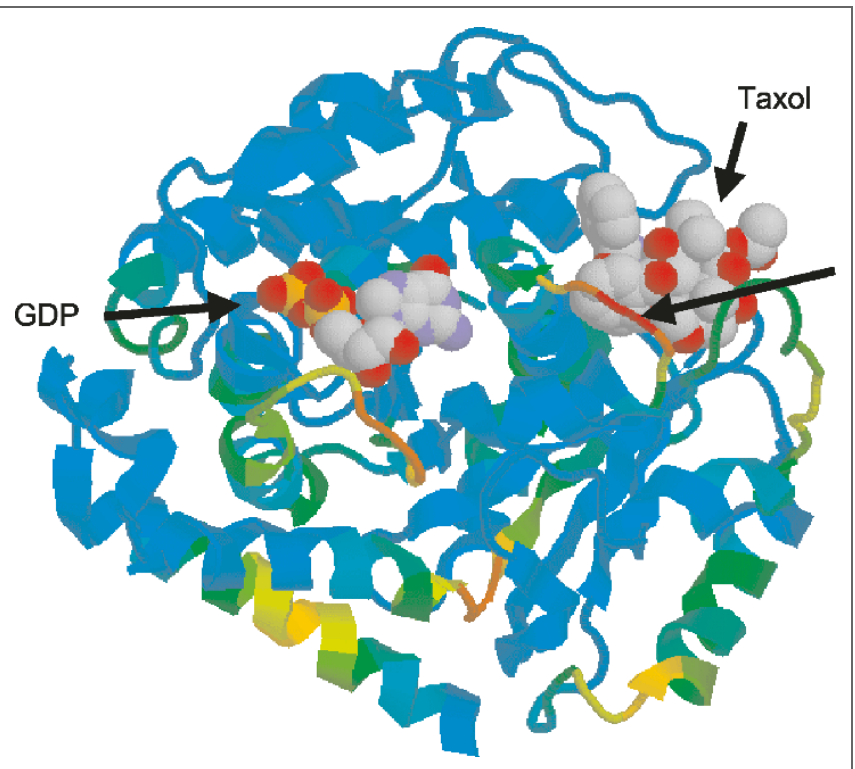

Figure I. Structure of $\beta$-tubulin rendered using colours to represent the similarity between the sequence of the protein and the sequences of dodecapeptides selected for affinity to $\mathrm{Taxol}^{\mathrm{TM}}$. Locations of bound GDP and Taxol ${ }^{\mathrm{TM}}$ are indicated by arrows. Red indicates a high level of similarity; blue a very low level. The highest similarity is in a segment forming a flexible loop about the Taxol ${ }^{\mathrm{TM}}$ binding partner for the drug doxorubicin. ${ }^{61}$ DNA-binding proteins were successfully affinity-selected from a yeast genomic library displayed on a $\lambda$ phage display vector. ${ }^{80}$ Carbohydrate-binding proteins have also been identified by similar techniques. ${ }^{81}$

These representative results demonstrate that, in cases where the targets can be successfully displayed in their proper three-dimensional configuration on the surface of phage particles, the use of cDNA expression product display libraries can provide a powerful approach to the identification of the molecular targets of small molecule drugs. Many targets, such as membrane proteins, however, may require other strategies, such as the fragmented epitope approaches mentioned above or the use of combinatorial peptide libraries outlined below.

\section{Combinatorial peptide libraries}

An alternative to the use of cDNA-expression product display is combinatorial peptide display. In this method, random synthetic oligonucleotides are inserted into the gene for a structural protein at a site known to be presented on the surface of the phage particle; the resulting population is screened for members exhibiting affinity for the small molecule probe using multiple rounds of biopanning. The sequences of the affinity-selected peptides are then

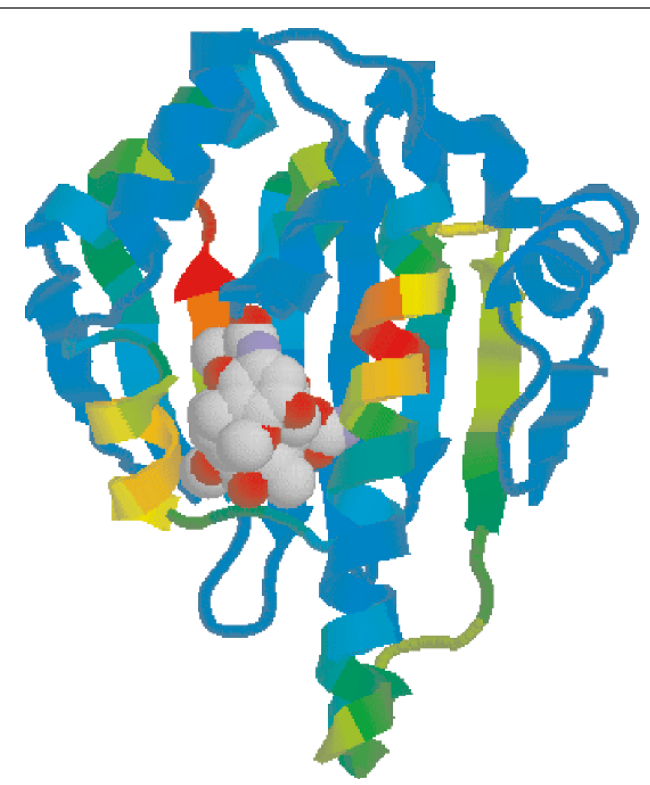

Figure 2. Structure of Hsp90 with bound geldamycin. Protein is rendered using colours to represent the similarity between the sequence of the protein and the sequences of peptides selected for affinity to Taxol ${ }^{\mathrm{TM}}$. Red indicates a high level of similarity, blue a very low level. Three segments with relatively high similarity scores bracket the geldamycin-binding site, suggesting that $\mathrm{Taxol}^{\mathrm{TM}}$ may bind to the same site 
compared with the sequences of naturally occurring proteins and those proteins with segments having the greatest sequence similarity to the affinity-selected peptides are identified as potential targets for the small molecule. This process has been successfully used to identify novel targets for small molecules, as well as to map the binding sites of small molecules on proteins. 3,58

The principal limitation of this technique is that, for a successful outcome, the binding properties of peptides on the surface of the phage must mimic the binding properties of similar sequences in naturally occurring proteins. This will not always be the case. Our understanding of how a protein recognises a small molecule has changed little since 1894, when Emil Fischer first proposed that '...enzyme and glucoside have to fit to each other like a lock and key...'. This metaphor of protein structure conveys an image of rigidity that belies the complexity of the process of molecular recognition. It is becoming increasingly clear that many binding sites exhibit significant disorder prior to interaction with a ligand, particularly small molecule-binding sites, with the proteinligand complex moving through a series of progressively lower energy states towards the bottom of a 'binding funnel' (similar to the proposed 'folding funnel' model for protein folding). ${ }^{82,83}$ The initial steps in the process of molecular recognition of a small molecule by a protein might well involve the interaction of a disordered segment of peptide with the small molecule, suggesting that the structural context of the interaction is far less important than implied by the 'lock and key' vision. ${ }^{58}$ In this case, peptides on the surface of a phage might well reflect the binding properties of peptide segments of naturally occurring proteins, at least during the initial 'handshake' stage of the binding process.

Elucidation of three-dimensional protein structures via X-ray crystallography and nuclear magnetic resonance spectroscopy has provided extensive evidence that small molecule-binding sites are made of short stretches of peptide, usually arising from different discontinuous portions of the polypeptide chain. This would suggest that the sequence of any one portion of the protein would make an energetically trivial contribution to the total binding energy. But a survey of the structures of protein-small molecule interactions has shown that virtually all ligands larger than 300 Daltons interact with at least five contiguous amino acids in at least one peptide segment, ${ }^{58}$ implying that there is an energetic 'hot spot' in the ligand-binding site similar to those identified in proteinprotein interactions via mutagenesis studies. ${ }^{84-86}$ A peptide segment, five amino acids in length, is adequate to define a binding motif identifiable on a genome-wide scan.

It may be possible to categorise small molecule-binding sites by their level of flexibility prior to ligand binding. Those binding sites that act most like the classical 'lock and key' are rigid prior to binding. Although these may be detected through the screening of cDNA display libraries, it is unlikely that they will be identified through affinity screening of peptide libraries. Detection of these receptors may be more amenable to cDNA display approaches as outlined above, or even to in silico docking approaches. Other sites may have rigid bases and flexible overlying peptides, as in examples presented in a survey by Freire. ${ }^{87}$ Portions of these binding sites appear to be detectable using peptide phage display (see Taxol ${ }^{\mathrm{TM}}$ discussion below). Finally, there appear to be proteins that are significantly disordered prior to binding a ligand, such as the bacterial quorum-sensing pheromone from Agrobacterium tumefaciens. ${ }^{88}$ These highly disordered binding sites may well be the most easily mimicked by the binding properties of peptides on the surface of phage particles and appear to be detectable through the use of peptide phage display (again, see Taxol ${ }^{\mathrm{TM}}$ discussion below). Initial successes with this approach suggest an important role for random peptide display as a drug target identification tool.

\section{The case of Taxol ${ }^{\mathrm{TM}}$}

Taxol $^{\mathrm{TM}}$ is a natural product with broad cytotoxic activity against a range of human tumours. It was first isolated from the bark of Pacific yew trees, and is now produced in a two-step semisynthesis from precursors extracted from the needles of farmed yew bushes. ${ }^{89}$ The primary activity of Taxol $^{\mathrm{TM}}$ is its cytotoxicity towards rapidly dividing cells, apparently brought on through p53-mediated apoptosis initiated by binding to $\beta$-tubulin, a process that induces microtubule bundling and halts mitosis.

\section{Isolation of Taxol ${ }^{\mathrm{TM}}$-selected peptides}

Libraries of random 12-mer and disulfide-bond cyclised random 7-mer peptides displayed at the amino terminus of the mature pIII of M13 phage were selected for members that exhibited affinity to a biotinylated derivative of Taxol $^{\mathrm{TM}}$ which had been immobilised on streptavidin-coated plates. ${ }^{3,58}$ The sequences of Taxol $^{\mathrm{TM}}$-selected peptides were analysed in three ways: (i) The sequences of proteins known to bind to Taxol $^{\mathrm{TM}}$ were compared with the Taxol ${ }^{\mathrm{TM}}$-selected sequences as an internal control;

(ii) the sequences of Taxol ${ }^{\mathrm{TM}}$-selected peptides were analysed to identify motifs that occurred in multiple peptides and these motifs were used to search the human genome database for novel $\mathrm{Taxol}^{\mathrm{TM}}$-binding proteins; and (iii) the full-length sequences of the Taxol ${ }^{\mathrm{TM}}$-selected peptides were compared with the sequences of proteins on a genome-wide scale to identify those proteins with regions exhibiting sequences with high similarity to the $\operatorname{Taxol}^{\mathrm{TM}}$-selected peptide population.

Only weak consensus sequences were found within either of the two selected peptide populations; however, the physicochemical properties of the selected phage populations were statistically evaluated and found to be substantially different from that of an unselected population. ${ }^{3}$ This observation suggested that, in spite of the absence of a strong consensus sequence, the selection process had been successful. A comparison of the Taxol ${ }^{\mathrm{TM}}$-binding peptide sequences to known Taxol $^{\mathrm{TM}}$-binding proteins was carried out to determine if any peptides were mimicking known Taxol $^{\mathrm{TM}}$-binding motifs. 


\section{Comparison of the Taxol ${ }^{\mathrm{TM}}$-selected peptides to the sequence of $\beta$-tubulin}

Initial comparison of sequence motifs from the $\mathrm{Taxol}^{\mathrm{TM}}$ selected populations with the sequence of human $\beta$-tubulin suggested no detectable similarity. ${ }^{3}$ The development of algorithms which made it possible to compare the complete sequences of all the selected peptides with the sequences of naturally occurring proteins allowed for the detection of similarities between the sequences of the Taxol ${ }^{\mathrm{TM}}$-binding peptides and the sequence of $\beta$-tubulin, however. ${ }^{58}$ Figure 1 is a depiction of the three-dimensional structure of $\beta$-tubulin, in which the colour table has been chosen to reflect the similarity of the tubulin sequence to that of the random 12-mers selected for affinity to Taxol ${ }^{\mathrm{TM}}$. Examination of this Figure indicates that the region of highest similarity is a surface loop in direct contact with the bound Taxol ${ }^{\mathrm{TM}}$. This may be an example of the rigid base/flexible overlying loop scenario discussed above. Figure 1 demonstrates that the sequence of at least one segment of $\beta$-tubulin involved in $\mathrm{Taxol}^{\mathrm{TM}}$ binding is a weak motif within the sequences of the Taxol ${ }^{\mathrm{TM}}$-selected peptides. Nevertheless, the representation of this putative Taxol ${ }^{\mathrm{TM}}$ binding motif is relatively weak in the Taxol $^{\mathrm{TM}}$-selected peptide population. Although the surface loop in contact with the Taxol $^{\mathrm{TM}}$ molecule exhibits the highest similarity to the sequences of the Taxol ${ }^{\mathrm{TM}}$-selected peptides in $\beta$-tubulin, this similarity is not exceptionally high in comparison with that found when scanning the entire genome.

A similar comparison of the affinity-selected conformationally constrained 7-mer population with that of $\beta$-tubulin indicated that the protein segment of highest similarity to the peptides was remote from the Taxol $^{\mathrm{TM}}$-binding site, but that the second-highest similarity peak corresponded to a protein segment in direct contact with Taxol $^{\mathrm{TM}}$ (results not shown). Again, the observed level of similarity was not exceptional in comparison with whole genome scanning.

\section{Other Taxol ${ }^{\mathrm{TM}}$-binding proteins}

A comparison of the sequence of the human multi-drug transporter MDR 1 (P-glycoprotein) to the sequences of Taxol ${ }^{\mathrm{TM}}$ selected peptides resulted in the prediction of two putative Taxol $^{\mathrm{TM}}$-binding regions within the $\mathrm{P}$-glycoprotein sequence. ${ }^{58}$ Both of these regions fall within the putative drug-binding regions of the protein that have been identified previously using photo-affinity labelling, ${ }^{4,5}$ demonstrating that the data are consistent with those peptides possessing Taxol $^{\mathrm{TM}}$-binding motifs.

Using biotin-labelled Taxol ${ }^{\mathrm{TM}}$, Byrd et al. identified two Taxol $^{\mathrm{TM}}$ targets from both mouse macrophages and brain as heat shock proteins of the $70-$ and $90-\mathrm{kDa}$ families. ${ }^{8}$ The structure of Hsp90 bound to geldamycin, a specific inhibitor of the Hsp90 family, has been elucidated. ${ }^{90}$ The Hsp90 sequence has three segments exhibiting similarity to the sequences of the Taxol ${ }^{\mathrm{TM}}$-selected peptides. Two of these are in alpha-helical structures that flank the geldamycin binding site; the third is at the end of a beta strand beneath the geldamycinbinding site, as shown in Figure 2. These results, when compared with the previous analyses, predict that Taxol $^{\mathrm{TM}}$ will bind Hsp90 at the same site as geldamycin.

Experimental evidence from affinity chromatography suggests that Taxol $^{\mathrm{TM}}$ interacts with murine CD18 in a manner mimicking that of lipopolysaccharide to produce an inflammatory response. ${ }^{6}$ Although the three-dimensional structure of one subunit of CD18 has been elucidated and the Taxol ${ }^{\mathrm{TM}}$ selected peptides have been used to predict regions with high probability of binding $\operatorname{Taxol}^{\mathrm{TM}}$, there are no biochemical data available to evaluate the Taxol ${ }^{\mathrm{TM}}$-binding site on CD18 predicted by this analysis.

\section{Genome-wide survey of Taxol ${ }^{\mathrm{TM}}$-binding motifs}

An analysis of the Taxol ${ }^{\mathrm{TM}}$-selected peptides identified several sequence motifs which appeared multiple times in the peptides. Sequences of all proteins in the human genome database were searched to identify proteins containing these sequences. This process led to the identification of the anti-apoptotic protein $\mathrm{Bcl}-2$ as a candidate Taxol $^{\mathrm{TM}}$-binding protein containing the amino acid sequence motif HTPHP. Enzyme-linked immunosorbent assay binding studies and circular dichroism spectroscopy were used to show that the affinity of $\mathrm{Taxol}^{\mathrm{TM}}$ for $\mathrm{Bcl}-2$ is in the $200 \mathrm{nM}$ range. ${ }^{3}$ Calculation of the similarity of the Taxol ${ }^{\mathrm{TM}}$-selected peptides to the sequence of Bcl-2 indicated that the most likely site for the binding of Taxol ${ }^{\mathrm{TM}}$ to $\mathrm{Bcl}-2$ was within a 50 amino acid unstructured loop near the amino terminus of the protein. A model of the three-dimensional structure of Bcl-2 is shown in Figure 3. This model is based upon the three-dimensional structure of $\mathrm{Bcl}-\mathrm{X}_{\mathrm{L}}{ }^{91}$ and the more recent structures of $\mathrm{Bcl}-2$, in which the unstructured loop was excised and replaced by the corresponding sequence from $\mathrm{Bcl}-\mathrm{X}_{\mathrm{L}} .{ }^{92}$

\section{The significance of the Taxol $^{\mathrm{TM}}-\mathrm{Bcl}-2$ interaction}

Is the interaction of Taxol $^{\mathrm{TM}}$ with $\mathrm{Bcl}-2$ relevant to the clinical activity of Taxol $^{\mathrm{TM}}$ ? It has long been known that Bcl-2 is phosphorylated and inactivated in cells treated with $\mathrm{Taxol}^{\mathrm{TM}} .^{93,94}$ This inactivation blocks the anti-apoptotic activity of Bcl-2, leading to apoptosis, a major mechanism of the cytotoxic activity of Taxol $^{\mathrm{TM}}$. It has been noted, however, that Taxol ${ }^{\mathrm{TM}}$ is a much more potent anti-cancer drug than other tubulin-binding mitotic spindle poisons. Experiments have pointed to the existence of a non-p53-dependent pathway towards apoptosis subsequent to the addition of Taxol ${ }^{\mathrm{TM}}$ to the cell culture. ${ }^{95-97}$

The direct interaction of Taxol ${ }^{\mathrm{TM}}$ with $\mathrm{Bcl}-2$ may mediate a predicted alternative pathway to apoptosis, independent of mitotic block and the subsequent activity of p53. This hypothesis was reinforced when it was shown that application of Taxol ${ }^{\mathrm{TM}}$ to isolated mitochondria ${ }^{98}$ induced the 


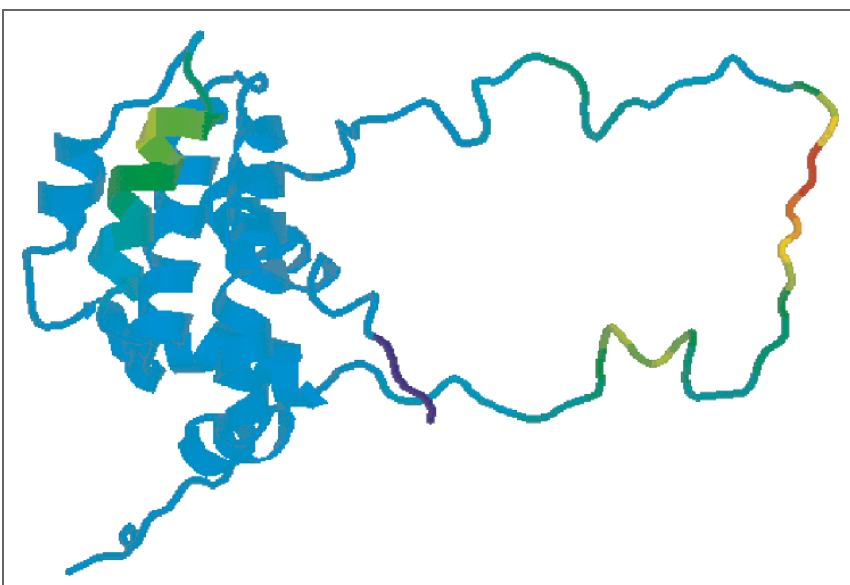

Figure 3. A model of the three-dimensional structure of Bcl-2. This model is based on the three-dimensional structure of $\mathrm{Bcl}-\mathrm{X}_{\mathrm{L}}$ (pdb file $\mathrm{ILXL} \mathrm{L}^{103}$ ) and the more recent structures of $\mathrm{Bcl}-2$ in which the unstructured loop was excised and replaced by the corresponding sequence from $\mathrm{Bcl}-\mathrm{X}_{\mathrm{L}}$ (pdb file $\mathrm{IGJ} \mathrm{H}^{104}$ ). Protein is rendered using colours to represent the similarity between the sequence of the protein and the sequences of peptides selected for affinity to Taxol ${ }^{\mathrm{TM}}$. Red indicates a high level of similarity, blue a very low level. The highest level of similarity is in the flexible 50 amino acid loop, which has no structure detectable either from $\mathrm{X}$-ray crystallography or nuclear magnetic resonance spectroscopy, and is thus highly mobile in solution

permeability transition that results in the release of cytochrome c, an obligate step in the apoptotic pathway. Bcl-2 is anchored in the outer membrane of mitochondria through a C-terminal tail, making it a potential mitochondrial target for mediating this activity. Although tubulin has also been shown to be a component of mitochondrial membranes, ${ }^{99}$ making it possible that interaction with tubulin also induces this activity, the functional connection between tubulin and the molecular events involved in the mitochondrial permeability transition has been shown to involve Bcl-2. Removal of the flexible loop of Bcl-2 blocks the apoptotic action of Taxol ${ }^{\mathrm{TM}},{ }^{100,101}$ as does phosphorylation. ${ }^{102}$ It is a reasonable hypothesis that when this flexible regulatory loop is bound to Taxol ${ }^{\mathrm{TM}}, \mathrm{Bcl}-2$ is incapable of preventing the progression to apoptosis.

\section{Whole-genome similarity calculations}

In the genome-wide scan for potential Taxol ${ }^{\mathrm{TM}}$-binding proteins, the authors identified a single protein, Bcl-2, that has since been shown to exhibit significant affinity for Taxol ${ }^{\mathrm{TM}} .^{3}$ None of the previously known Taxol ${ }^{\mathrm{TM}}$-targets were identified in this scan. There are several possible reasons for this, some technical and some fundamental. From a technical perspective, only 69 peptides selected for binding to Taxol ${ }^{\mathrm{TM}}$ were used for this novel ligand identification. In their more recent work, aimed at the identification of ATP-binding proteins
(Makowski et al., 2003; in preparation), the authors routinely use the sequences of 500 affinity-selected peptides for genome-wide scans. While other Taxol ${ }^{\mathrm{TM}}$-binding motifs were present in the Taxol ${ }^{\mathrm{TM}}$-selected peptides, such as those matching the $\beta$-tubulin and $\mathrm{P}$-glycoprotein sequences, these were less strongly represented than the motif found in Bcl-2. Sequencing of a larger number of peptide sequences makes it possible to observe multiple copies of the motifs that exhibit affinity for the target small molecule, greatly enhancing the likely success of a genome-wide search.

A more fundamental consideration is the fact that $\operatorname{Taxol}^{\mathrm{TM}}$ binding to Bcl-2 involves a 50 amino acid flexible loop, a structural context readily mimicked by the phage-displayed peptides. The Taxol ${ }^{\mathrm{TM}}$-binding sites in the previously identified target structures (eg $\beta$-tubulin) appear to be more rigidly structured, involving several discontinuous segments of peptide. Any one peptide segment involved in a relatively rigid binding site may correspond to a motif that exhibits relatively low affinity on its own, leading to a relatively lower abundance in the affinity-selected peptides. These short motifs are observable these loops were picked out in a scan of the individual proteins as the most likely site within the protein to be involved in binding of Taxol $^{\mathrm{TM}}$ - but their observation in a genome-wide scan presents a formidable signal-to-noise problem. Careful analysis of the results of the authors' ongoing study of ATP-binding peptides, utilising the extensive body of knowledge available for ATP-binding proteins, is being used to provide a basis for further development of genome-wide methods.

\section{Concluding remarks}

The results from the Taxol ${ }^{\mathrm{TM}}$ affinity screening suggest that the utilisation of combinatorial peptide phage display to identify novel drug targets will be most successful for targets with binding sites that are highly flexible prior to ligand binding. Considerable technical improvements in the current methods are possible, both experimental and algorithmic, and the greatest potential is for identification of disordered binding sites that are difficult to find by other methods. cDNA and other display methods may be more appropriate for finding binding sites that involve relatively rigid constructs or multiple punctate interactions with short peptide segments. In silico docking methods for the prediction of binding sites are also more likely to be successful in the identification of rigid binding sites in target proteins. A complete accounting of the binding repertoire of a small molecule drug will require a combination of methods, each best suited to a subset of the potential targets.

The results outlined here indicate that utilisation of phage display of cDNA expression products and random peptides holds significant promise as a strategy for identification of all the protein targets of a small molecule, as well as identification of specific regions in those proteins that may be involved in the binding process. 


\section{Acknowledgments}

We thank B. Kay for comments on the manuscript and S. Mandava for continuing assistance with the similarity calculations. This work was funded by a grant from the Lucille P. Markey Foundation to L.M. Continued support for development of these methods comes from the Office of Biological and Environmental Research, Department of Energy under Contract No. W-31-109-Eng-38 to D.J.R.

\section{References}

1. Drew, J. (2000), 'Drug discovery: A historical perspective', Science Vol. 287, pp. 1960-1964.

2. Schiff, P.B., Fant, J. and Horwitz, S.B. (1979), 'Promotion of microtubule assembly in vitro by taxol', Nature Vol. 277, pp. 665-667.

3. Rodi, D.J., Janes, R.W., Sanganee, H.J. et al. (1999), 'Screening a library of phage-displayed peptides identifies human Bcl-2 as a Taxol ${ }^{\mathrm{TM}}$-binding protein', J. Mol. Biol. Vol. 285, pp. 197-204.

4. Wu, Q., Bounard, P.Y., Kuduk, S.D. et al. (1998), 'Identification of the domains of photoincorporation of the 3- and 7-benzophenone analogues of Taxol $^{\mathrm{TM}}$ in the carboxyl-terminal half of murine mdr1b P-glycoprotein', Biochemistry Vol. 37, pp. 11272-11279.

5. Ambudkar, S.V., Dey, S., Hrycyna, C.A. et al. (1999), 'Biochemical, cellular and pharmacological aspects of the multi-drug transporter', Ann. Rev. Pharmacol. Toxicol. Vol. 39, pp. 361-398.

6. Bhat, N., Perera, P.Y., Carboni, J.M. et al. (1999), 'Use of a photoactivatable $\mathrm{Taxol}^{\mathrm{TM}}$ analogue to identify unique cellular targets in murine macrophages: Identification of murine $\mathrm{CD} 18$ as a major Taxol ${ }^{\mathrm{TM}}$-binding protein and a role for Mac-1 in Taxol ${ }^{\mathrm{TM}}$-induced gene expression', J. Immunol. Vol. 162, pp. 7335-7342.

7. Dhawan, V. and Swaffar, D.S. (1999), 'A unique paclitaxel-mediated modulation of the catalytic activity of topoisomerase II $\alpha$ ', Anticancer Drugs Vol. 10, pp. 397-404.

8. Byrd, C.A., Bornmann, W., Erdjument-Bromage, H. et al. (1999), 'Heat shock protein 90 mediates macrophage activation by Taxol ${ }^{\mathrm{TM}}$ and bacterial lipopolysacchride', Proc. Natl. Acad. Sci. USA Vol. 96, pp. 5645-5650.

9. Vane, J.R. (1971), 'Inhibition of prostaglandin synthesis as a mechanism of action for aspirin-like drugs', Nat. New Biol. Vol. 231, pp. 232-235.

10. Yin, M.-J., Yamamoto, Y. and Gaynor, R.B. (1998), 'The anti-inflammatory agents aspirin and salicylate inhibit the activity of ІкB kinase $\beta$ ', Nature Vol. 396, pp. 77-80.

11. Puscas, I., Coltau, M. and Pasca, R. (1996), 'Nonsteroidal anti-inflammatory drugs activate carbonic anhydrase by a direct mechanism of action', J. Pharmacol. Exp. Ther. Vol. 277, pp. 1464-1466.

12. Villanueva, G.B. and Allen, N. (1986), 'Acetylation of antithrombin III by aspirin', Semin. Thromb. Hemost. Vol. 12, pp. 213-215.

13. Glasgow, J.F., Middleton, B., Moore, R. et al. (1999), 'The mechanism of inhibition of beta-oxidation by aspirin metabolites in skin fibroblasts from Reyes syndrome patients and controls', Biochim. Biophys. Acta. Vol. 1454, pp. $115-125$.

14. Kawashima, Y., Nakagawa, S., Tachibana, Y. and Kozuka, H. (1983), 'Effects of peroxisome proliferators on fatty acid-binding protein in rat liver', Biochim. Biophys. Acta Vol. 754, pp. 21-27.

15. Woodcock, J., Moazed, D., Cannon, M. et al. (1991), 'Interaction of antibiotics with A- and P-site-specific bases in 16S ribosomal RNA', EMBO J. Vol. 10, pp. 3099-3103.

16. Rothlin, C.V., Katz, E., Verbitsky, M. et al. (2000), 'Block of the $\alpha 9$ nicotinic receptor by ototoxic aminoglycosides', Neuropharmacology Vol. 39, pp. 2525-2532.

17. Ylikoski, J., Xing-Qun, L., Virkkala, J. and Pirvola, U. (2002), 'Blockade of c-Jun N-terminal kinase pathway attenuates gentamicin-induced cochlear and vestibular hair cell death', Hear. Res. Vol. 163, pp. 71-81.
18. Bryla, J., Lietz, T., Jarzyna, R. et al. (1992), 'Differential in vivo and in vitro effect of gentamicin on glutamate synthesis and glutamate deamination in rabbit kidney-cortex tubules and mitochondria', Pharmacol. Res. Vol. 26, pp. $367-375$.

19. Ghosh, S. and Dasgupta, S. (1999), 'Gentamicin induced inhibition of steroidogenic enzymes in rat testis', Indian J. Physiol. Pharmacol. Vol. 43, pp. $247-250$.

20. Chavez, M.L. and DeKorte, C.J. (2003), 'Valdecoxib: A review', Clin. Ther. Vol. 25, pp. 817-851.

21. Bamforth, K.J., Dalgliesh, K. and Coughtrie, M.W. (1992), 'Inhibition of human liver steroid sulfotransferase activities by drugs: A novel mechanism of drug toxicity?', Eur. J. Pharmacol. Vol. 228, pp. 15-21.

22. Goodwin, J.S. (1984), 'Mechanism of action of nonsteroidal anti-inflammatory agents', Am. J. Med. Vol. 77, pp. 57-64.

23. Martin, J.A., Mobberley, M.A., Redshaw, S. et al. (1991), 'The inhibitory activity of a peptide derivative against the growth of simian immunodeficiency virus in C8166 cells', Biochem. Biophys. Res. Commun. Vol. 176, pp. $180-188$.

24. Lenhard, J.M., Furfine, E.S., Jain, R.G. et al. (2000), 'HIV protease inhibitors block adipogenesis and increase lipolysis in vitro', Antiviral Res. Vol. 47, pp. 121-129.

25. Fourmy, D., Recht, M.I., Blanchard, S.C. and Puglisi, J.D. (1996), 'Structure of the A site of Escherichia coli 16S ribosomal RNA complexed with an aminoglycoside antibiotic', Science Vol. 274, pp. $1367-1371$.

26. von Ahsen, U., Davies, J. and Schroeder, R. (1991), 'Antibiotic inhibition of group I ribozyme function', Nature Vol. 353, pp. $368-370$.

27. Mikkelsen, N.E., Brännvall, M., Virtanen, A. and Kirsebom, L.A. (1999), 'Inhibition of RNase P RNA cleavage by aminoglycosides', Proc. Natl. Acad. Sci. USA Vol. 96, pp. 6155-6160.

28. Gabev, E., Kasianowicz, J., Abbott, T. and McLaughlin, S. (1989), 'Binding of neomycin to phosphatidylinositol 4,5-bisphosphate (PIP2)', Biochim. Biophys. Acta. Vol. 979, pp. 105-112.

29. Wang, Y., Hamasaki, K. and Rando, R.R. (1997), 'Specificity of aminoglycoside binding to RNA constructs derived from the 16S rRNA decoding region and the HIV-RRE activator region', Biochemistry Vol. 36, pp. $768-779$.

30. Polidoro, G., Del Boccio, G., Di Ilio, C. et al. (1984), 'In vitro interaction of penicillins and cephalosporins with human placenta GSH S-transferase', Res. Commun. Chem. Pathol. Pharmacol. Vol. 46, pp. 411-423.

31. Wright, A.J. (1999), 'The penicillins', Mayo Clin. Proc. Vol. 74, pp. $290-307$.

32. Padovan, E., von Greyerz, S., Pichler, W.J. and Weltzien, H.U. (1999), 'Antigen-dependent and -independent IFN- $\gamma$ modulation by penicillins', J. Immunol. Vol. 162, pp. 1171-1177.

33. Ogawara, H., Akiyama, T., Ishida, J. et al. (1986), 'A specific inhibitor for tyrosine protein kinase from Pseudomonas', J. Antibiot. (Tokyo) Vol. 39, pp. 606-608.

34. Akiyama, T., Ishida, J., Nakagawa, S. et al. (1987), 'Genistein, a specific inhibitor of tyrosine-specific protein kinases', J. Biol. Chem. Vol. 262, pp. 5592-5595.

35. Traxler, P., Green, J., Mett, H. et al. (1999), 'Use of a pharmacophore model for the design of EGFR tyrosine kinase inhibitors: isoflavones and 3-phenyl-4(1H)-quinolones', J. Med. Chem. Vol. 42, pp. 1018-1026.

36. Okura, A., Arakawa, H., Oka, H. et al. (1988), 'Effect of genistein on topoisomerase activity and on the growth of [Val 12]Ha-ras-transformed NIH 3T3 cells', Biochem. Biophys. Res. Commun. Vol. 157, pp. 183-189.

37. Markovits, J., Linassier, C., Fosse, P. et al. (1989), 'Inhibitor effects of the tyrosine kinase inhibitor genistein on mammalian DNA topoisomerase II', Cancer Res. Vol. 49, pp. 5111-5117.

38. Pike, A.C.W., Brzozowski, A.M., Hubbard, R.E. et al. (1999), 'Structure of the ligand-binding domain of oestrogen receptor $\beta$ in the presence of a partial agonist and a full agonist', EMBO J. Vol. 18, pp. 4608-4618.

39. Margeat, E., Bourdoncle, A., Margueron, R. et al. (2003), 'Ligands differentially modulate the protein interactions of the human estrogen receptors $\alpha$ and $\beta$ ', J. Mol. Biol. Vol. 326, pp. 77-92. 
40. Wolfson, J.S. and Hooper, D.C. (1989), 'Fluoroquinolone antimicrobial agents', Clin. Microbiol. Rev. Vol. 2, pp. 378-424.

41. Heisig, P. (1996), 'Genetic evidence for a role of parC mutations in development of high-level fluoroquinolone resistance in Escherichia coli', Antimicrobial Agents Chemother. Vol. 40, pp. 879-885.

42. Varon, E., Janoir, C., Kitzis, M.-D. and Gutmann, L. (1999), 'ParC and GyrA may be interchangeable initial targets of some fluoroquinolones in Streptococcus pneumoniae', Antimicrobial Agents Chemother. Vol. 43, pp. 302-306.

43. Hamy, F., Felder, E.R., Heizmann, G. et al. (1997), 'An inhibitor of the Tat/TAR RNA interaction that effectively suppresses HIV-1 replication', Proc. Natl. Acad. Sci. USA Vol. 94, pp. 3548-3553.

44. Daelemans, D., Schols, D., Witvrouw, M. et al. (2000), 'A second target for the peptoid Tat/transactivation response element inhibitor CGP64222: inhibition of human immunodeficiency virus replication by blocking CXC0Chemokine receptor 4-mediated virus entry', Mol. Pharmacol. Vol. 57, pp. 116-124.

45. Sedlacek, H.H. (2001), 'Mechanisms of action of flavopiridol', Crit. Rev. Oncol. Hematol. Vol. 38, pp. 139-170.

46. Bible, K.C., Bible, Jr, R.H., Kottke, T.J. et al. (2000), 'Flavopiridol binds to duplex DNA', Cancer Res. Vol. 60, pp. 2419-2428.

47. Maxwell, A. (1997), 'DNA gyrase as a drug target', Trends Microbiol. Vol. 5, pp. $102-109$.

48. Kranz, R.G., Beckman, D.L. and Foster-Hartnett, D. (1982), 'DNA gyrase activities from Rhodobacter capsulatus: Analysis of target(s) of coumarins and cloning of the gyrB locus', FEMS Microbiol. Lett. Vol. 72, pp. 25-32.

49. Chen, X., Ji, Z.L. and Chen, Y.Z. (2002), 'TTD: therapeutic target database', Nucl. Acids Res. Vol. 30, pp. 412-415.

50. McNeal, J. (1998), 'Efforts in combinatorial chemistry', Todays Chemist at Work Vol. 7, pp. 34-36.

51. DiMasi, J.A., Bryant, N.R. and Lasagna, L. (1991), 'New drug development in the United States from 1963 to 1990', Clin. Pharmacol. Ther. Vol. 50, pp. 471-486.

52. Drews, J. (1997), 'Strategic choices facing the pharmaceutical industry: A case for innovation', Drug Discov. Today Vol. 2, pp. 72-78.

53. Zivin, J.A. (2000), 'Understanding clinical trials', Sci. Am. Vol. 282, pp. $69-75$.

54. Greene, N. (2002), 'Computer systems for the prediction of toxicity: An update', Adv. Drug Deliv. Rev. Vol. 54, pp. 417-431.

55. Cronin, M.T. (2003), 'Computer-aided prediction of drug toxicity and metabolism', EXS Vol. 93, pp. 259-278.

56. Wilson, A.G., White, A.C. and Mueller, R.A. (2003), 'Role of predictive metabolism and toxicity modeling in drug discovery - a summary of some recent advancements', Curr. Opin. Drug Discov. Devel. Vol. 6, pp. $123-128$.

57. Chen, Y.Z. and Ung, C.Y. (2001), 'Prediction of potential toxicity and side effect protein targets of a small molecule by a ligand-protein inverse docking approach', J. Mol. Graph. Model. Vol. 20, pp. 199-218.

58. Rodi, D.J., Agoston, G.E., Manon, R. et al. (2001), 'Identification of small molecule binding sites within proteins using phage display technology', Comb. Chem. High Throughput Screen. Vol. 4, pp. 553-572.

59. Sche, P.P., McKenzie, K.M., White, J.D. and Austin, D.J. (1999), 'Display cloning: Functional identification of natural product receptors using cDNA-phage display', Chem. Biol. Vol. 6, pp. 707-716.

60. Sche, P.P., McKenzie, K.M., White, J.D. and Austin, D.J. (2001), 'Corrigendum to: 'Display cloning: functional identification of natural product receptors using cDNA-phage display' [Chem. Biol., Vol. 6, pp. 707-716]', Chem. Biol. Vol. 8, pp. 399-400.

61. Jin, Y., Yu, J. and Yu, Y.G. (2002), 'Identification of hNopp140 as a binding partner for doxorubicin with a phage display cloning method', Chem. Biol. Vol. 9, pp. 157-162.

62. Darvas, F., Dorman, G., Urge, L. et al. (2001), 'Combinatorial chemistry. Facing the challenge of chemical genomics', Pure Appl. Chem. Vol. 73, pp. 1487-1498.

63. Newman, D.J., Cragg, G.M. and Snader, K.M. (2003), 'Natural products as sources of new drugs over the period 1981-2002', J. Nat. Prod. Vol. 66, pp. $1022-1037$.
64. Borman, S. (2002), 'Organic lab sparks drug discovery', Chem. Eng. News Vol. 80 , pp. $23-24$.

65. Phizicky, E., Bastiaens, P.I., Zhu, H. et al. (2003), 'Protein analysis on proteomic scale', Nature Vol. 422, pp. 208-215.

66. Graves, P.R., Kwiek, J.J., Fadden, P. et al. (2002), 'Discovery of novel targets of quinoline drugs in the human purine binding proteome', Mol. Pharmacol. Vol. 62, pp. 1364-1372.

67. Takahishi, T.T., Austin, R.J. and Roberts, R.W. (2003), 'mRNA display: Ligand discovery, interaction analysis and beyond', Trends Biochem. Sci. Vol. 28, pp. 159-165.

68. Lee, S.Y., Choi, J.H. and Xu, Z. (2003), 'Microbial cell-surface display', Trends Biotechnol. Vol. 21, pp. 45-52.

69. Williams, C. (2003), 'Biotechnology match making: Screening orphan ligands and receptors', Curr. Opin. Biotechnol. Vol. 11, pp. 42-46.

70. McPherson, M., Yang, Y.F., Hammond, P.W. and Kreider, B.L. (2002), 'Drug receptor identification from multiple tissues using cellular-derived mRNA display libraries', Chem. Biol. Vol. 9, pp. 691-698.

71. Scott, J.K. and Barbas, C.F. III (2001), 'Phage-display vectors', in Barbas, C.F., III, ed., Phage Display: A Laboratory Manual, Cold Spring Harbor Laboratory Press, Cold Spring Harbor, NY, pp. 2.1-2.19.

72. Scott, J.K. and Smith, G.P. (1990), 'Searching for peptide ligands with an epitope library', Science Vol. 249, pp. 386-390.

73. Rodi, D.J., Soares, A. and Makowski, L. (2002), 'Quantitative assessment of peptide sequence diversity in M13 combinatorial peptide phage display libraries', J. Mol. Biol. Vol. 322, pp. 1039-1052.

74. Castagnoli, L., Zucconi, A., Quondam, M. et al. (2001), 'Alternative bacteriophage display systems', Comb. Chem. High Throughput Screen. Vol. 4, pp. 121-133.

75. Santantelo, G.M., Tornow, J. and Moldave, K. (1986), 'Cloning of open reading frames and promoters from the Sacharomyces cervisiae genome: Construction of genomic libraries of random small fragments', Gene Vol. 46, pp. 181-186.

76. Bluthner, M., Bautz, E.K.F. and Bautz, F.A. (1996), 'Mapping of epitopes recognized by $\mathrm{PM} / \mathrm{Scl}$ autoantibodies with gene-fragmented phage display libraries', J. Immunol. Methods Vol. 198, pp. 187-198.

77. Jacobsson, K. and Frykberg, L. (1998), 'Gene VIII-based phage-display vectors for selection against complex mixtures of ligands', BioTechniques Vol. 24, pp. 294-301.

78. Cochrane, D., Webster, C., Masih, G. and McCafferty, J. (2000), 'Identification of natural ligands for $\mathrm{SH} 2$ domains from a phage display cDNA library', J. Mol. Biol. Vol. 297, pp. 89-97.

79. Robben, J., Hertveldt, K., Bosmans, E. and Volckaert, G. (2002), 'Selection and identification of dense granule antigen GRA3 by Toxoplasma gondii whole genome phage display', J. Biol. Chem. Vol. 277, pp. 17544-17547.

80. Hagiwara, H., Kunihiro, S., Nakajima, K. et al. (2002), 'Affinity selection of DNA-binding proteins from yeast genomic DNA libraries by improved lambda phage display vector', J. Biochem. (Tokyo) Vol. 132, pp. 975-982.

81. Yamamoto, M., Kominato, Y. and Yamamoto, F. (1999), 'Phage display cDNA cloning of protein with carbohydrate affinity', Biochem. Biophys. Res. Commun. Vol. 16, pp. 194-199.

82. Tsai, C.-J., Ma, B. and Nussinov, R. (1999), 'Folding and binding cascades: Shifts in energy landscapes', Proc. Natl. Acad. Sci. USA, Vol. 96, pp. 9970-9972.

83. Tsai, C.-J., Kumar, S., Ma, B. and Nussinov, R. (1999), 'Folding funnels, binding funnels and protein function', Protein Sci. Vol. 8, pp. $1181-1190$.

84. Clackson, T. and Wells, J.A. (1995), 'A hot spot of binding energy in a hormone-receptor interface', Science Vol. 267, pp. 383-386.

85. Dwyer, J.J., Dwyer, M.A. and Kossiakoff, A.A. (2001), 'High affinity RNase S-peptide variants obtained by phage display have a novel hot-spot of binding energy', Biochemistry Vol. 40, pp. 13491-13500.

86. Scott, J.K., Huang, S.-F., Gangadhar, B.P. et al. (2001), 'Evidence that a protein-protein interaction hot spot on heterotrimeric G protein $\gamma$ subunits is used for recognition of a subclass of effectors', EMBO J. Vol. 20, pp. $767-776$. 
87. Freire, E. (1999), 'The propagation of binding interactions to remote sites in proteins: Analysis of the binding of the monoclonal antibody D1.3 to lysozyme', Proc. Natl. Acad. Sci. USA, Vol. 96, pp. 10118-10122.

88. Zhang, R.G., Pappas, T., Brace, J.L. et al. (2002), 'Structure of a bacterial quorum-sensing transcription factor complexed with pheromone and DNA', Nature Vol. 417, pp. 971-974.

89. Georg, G.I., Chen, T.T., Ojima, I. and Vyas, D.M. (Eds.) (1995), 'Taxane anticancer agents. Basic science and current status', ACS Symp. Ser,, Vol. 583, Washington, DC.

90. Stebbins, C.E., Russo, A.A., Schneider, C. et al. (1997), 'Crystal structure of an Hsp90-geldamycin complex; targeting of a protein chaperone by an anti-tumor agent', Cell Vol. 89, pp. 239-252.

91. Muchmore, S.W., Sattler, M., Liang, H. et al. (1996), 'X-ray and NMR structure of human Bcl-xL, an inhibitor of programmed cell death', Nature Vol. 381, pp. 335-339.

92. Petros, A.M., Medek, A., Nettesheim, D.G. et al. (2001), 'Solution structure of the anti-apoptotic protein Bcl-2', Proc. Natl. Acad. Sci. USA Vol. 98, pp. 3012-3016.

93. Maundrell, K., Antonsson, B., Magnenat, E. et al. (1997), 'Bcl-2 undergoes phosphorylation by c-Jun N-terminal kinase/stress-activated protein kinases in the presence of the constitutively active GTP-binding protein Rac1', J. Biol. Chem. Vol. 272, pp. 25238-25242.

94. Ito, T., Deng, X., Carr, B. and May, W.S. (1997), 'Bcl-2 phosphorylation required for anti-apoptosis function', J. Biol. Chem. Vol. 272, pp. $11671-11673$.

95. Woods, C.M., Zhu, J., McQueney, P.A. et al. (1995), 'Taxol-induced mitotic block triggers rapid onset of a p53-independent apoptotic pathway', Mol. Med. Vol. 1, pp. 506-526.
96. Jordan, M.A., Wendell, K., Gardiner, S. et al. (1996), 'Mitotic block induced in HeLa cells by low concentrations of paclitaxel (Taxol) results in abnormal mitotic exit and apoptotic cell death', Cancer Res. Vol. 56, pp. $816-825$.

97. Lieu, C.H., Yang, Y.N. and Lai, Y.K. (1997), 'Dual cytotoxic mechanisms of submicromolar taxol on human leukemia HL-60 cells', Biochem. Pharmacol. Vol. 53, pp. 1587-1596.

98. Andre, N., Carre, M., Brasseur, G. et al. (2002), 'Paclitaxel targets mitochondria upstream of caspase activation in intact human neuroblastoma cells', FEBS Lett. Vol. 532, pp. 256-260.

99. Carre, M., Andre, N., Carles, G. et al. (2002), 'Tubulin is an inherent component of mitochondrial membranes that interacts with the voltage-dependent anion channel', J. Biol. Chem. Vol. 277, pp. 33664-33669.

100. Srinivastava, R., Mi, Q.-S., Hardwick, J.M. and Longo, D.L. (1999), 'Deletion of the loop region of Bcl-2 completely clocks paclitaxelinduced apoptosis', Proc. Natl. Acad. Sci. USA Vol. 96, pp. 3775-3780.

101. Wang, S., Wang, Z., Biose, L. et al. (1999), 'Loss of the Bcl-2 phosphorylation loop domain increases resistance of human leukemia cells to paclitaxel-mediated mitochondrial dysfunction and apoptosis', Biochem. Biophys. Res. Commun. Vol. 259, pp. 67-72.

102. Haldar, S., Basu, A. and Croce, C.M. (1998), 'Serine-70 is one of the critical sites for drug-induced Bcl2 phosphorylation in cancer cells', Cancer Res. Vol. 58, pp. 1609-1615.

103. Muchmore, S.W., Sattler, M., Liang, H. et al. (1996), 'X-ray and NMR structure of human Bcl-xL, an inhibitor of programmed cell death', Nature Vol. 381, pp. 335-339.

104. Petros, A.M., Medek, A., Nettesheim, D.G. et al. (2001), 'Solution structure of the anti-apoptotic protein Bcl-2', Proc. Natl. Acad. Sci. USA Vol. 98, pp. 3012-3016. 